Article

\title{
Effects of Vine Water Status and Exogenous Abscisic Acid on Berry Composition of Three Red Wine Grapes Grown under Mediterranean Climate
}

\author{
Massimiliano Cocco, Luca Mercenaro *, Mauro Lo Cascio ${ }^{\circledR}$ and Giovanni Nieddu \\ Department of Agriculture, University of Sassari, Viale Italia 39, 07100 Sassari, Italy; \\ massicocco@gmail.com (M.C.); mlocascio@uniss.it (M.L.C.); gnieddu@uniss.it (G.N.) \\ * Correspondence: mercenar@uniss.it
}

Received: 10 December 2019; Accepted: 25 January 2020; Published: 7 February 2020

\begin{abstract}
Beyond climatic conditions, qualitative performance is led by the intrinsic characteristics of the genotype. The aim of this study was to investigate the relationship between vine water status and exogenous abscisic acid (ABA) application on berry composition of the cultivars Cannonau, Merlot and Sangiovese. The experiment, carried out in 2016 and 2017, consisted of comparing two levels of irrigation treatments, full irrigation versus a non-irrigation treatment. Within each treatment, two sub-treatments were set up: (i) $4 \mathrm{~mL} \mathrm{~L}^{-1}$ of exogenous ABA applied at veraison to clusters only and subsequently repeated after six days; (ii) a control (untreated vines). The application of different irrigation regimes confirmed that the response to water stress is highly cultivar-dependent. Berry composition was influenced differently among cultivars by water stress. In terms of metabolites, positive influences were observed with Cannonau. No significant effects were observed by spraying exogenous ABA directly on grapes. Moreover, no significant interactions were found between the application of water stress and ABA. Exogenous ABA application did not appear to be a viticultural practice capable of influencing must composition in environments characterized by severe environmental conditions such as heat and drought.
\end{abstract}

Keywords: anthocyanin; water stress; grapevine; exogenous ABA; polyphenols; viticultural practice

\section{Introduction}

Grape quality can be described as the result of the balanced accumulation of primary and secondary compounds influenced by complex interactions between different factors [1]. In this context, the water-plant interaction has been an area of specific attention in recent years [2,3]. It is generally accepted that moderate water stress positively influences wine composition mainly due to the increasing skin/pulp ratio [4] and the biosynthesis of secondary metabolites [5]. While primary and secondary metabolites are positively affected by water stress, berry composition is determined by the interplay between soil water availability, atmospheric conditions [6] and genetic factors [7]. In fact, in Mediterranean environments where it is not traditionally practiced, irrigation is increasingly being used to allow berries to ripen properly as a response to ongoing climate change.

Grapevine cultivars have been described as isohydric or anisohydric depending on their response to soil water stress [8]. Isohydric cultivars are characterized by keeping their leaf water potential above a certain threshold regardless of the soil water availability and/or the atmospheric water demand. In contrast, cultivars behave as anisohydric when their leaf water potential drops in response to decreasing soil water availability or increasing atmospheric water demand [9]. It is important to underline that the same varieties have shown, in some cases, contrasting behaviours, probably due to different field experiment conditions [2]. Tombesi et al. [10] suggested representing grapevine varieties 
as a continuum of genotypes with different levels of anisohydry. It is well known that, when the plant perceives water shortage in the soil, both hydraulic and chemical signals are thought to be involved in the plant response [9].

Abscisic acid has been proposed as the main mediator of grapevine biological responses to abiotic stress, especially drought [11]. Furthermore, stomatal closure could be induced by hydraulic signals and maintained by abscisic acid (ABA) in drought-stressed grapevines, although both hydraulic and chemical signals coexist [12]. The study of such mechanisms is hindered by difficulties since growth regulators like ABA are involved in different processes. Evidence that exogenous ABA application can enhance sugar and anthocyanins in grape berries is strong [13-16]. The onset of ripening (veraison) was found to be related to sugar accumulation and was complemented by a marked increase in ABA concentration. Recent studies showed that an increase in ABA represents, in terms of time, the earliest event during the onset of ripening, followed by further increases in abscisic acid, and the accumulation of sugar, which are all integral for colour development [17]. Even though ABA concentration increases at veraison and then subsequently declines to a low level [14], both pre-and post-veraison water deficits alter the ABA accumulation patterns, influencing the level of sugar and phenolic substances [18]. Water deficit or exogenous ABA can significantly affect grape and wine phenolic compounds, as previously reported [19]. Moreover, ABA supply increases catechin and malvidin synthesis in both well-irrigated and moderately water-stressed vines, whereas resveratrol was enhanced only in water-stress conditions [20].

Even though the grapevine is well-adapted to semi-arid climate environments [2], post-veraison water deficit is in general a common strategy utilized to improve fruit composition in many wine-growing regions. Nowadays, water stress could be particularly severe in some areas of the planet due to climate change, and especially when associated with dry winters and springs, with the consequence that negative repercussions could occur affecting grape and wine quality. In order to target the desired berry traits, the understanding of the interactions between different cultivars and environmental aspects related to water stress represents an important issue for managing irrigation scheduling in a proper way. For these reasons, the aim of the present study was to evaluate the effect of water stress and the application of abscisic acid on the accumulation of primary and secondary metabolites in berries growing in a Mediterranean area, periodically subjected to severe water deficit during the post-veraison period.

\section{Materials and Methods}

\subsection{Experimental Design}

A field experiment was carried out in 2016 and 2017 in an experimental vineyard sited in Santa Maria la Palma-Alghero, Sardinia, Italy (40³9'20.31 ’ N; $8^{\circ} 16^{\prime} 0.26^{\prime \prime} \mathrm{E} ; 28$ meters above sea level). The site has a relatively uniform calcareous alluvial soil, with an average depth of $60-70 \mathrm{~cm}$, and the following physic-chemical characteristics: Sand 51.0\%, clay $24.9 \%$, silt $24.1 \%$; $\mathrm{pH}=7.44$; organic matter content $=16 \mathrm{~g} \mathrm{~kg}^{-1}$. The area is characterized by a typical central Mediterranean climate, with mild winters and hot, dry summers, with precipitation concentrated between October and May. Daily temperature, relative humidity and rainfall were recorded during the study by a weather station near the vineyard. Measurements were carried out on the cultivars Cannonau (synonym Grenache), Sangiovese and Merlot, planted in 2007, grafted on 1103 Paulsen rootstock and trained on a lateral spur-pruned cordon with the shoots vertically positioned and a canopy height of about $1.70 \mathrm{~m}$. The vines were manually pruned during the winter. The soil was managed by mowing natural herbage during the winter-spring period and through mechanical weed control in the summer. Weeds along the row were controlled by herbicide application. The plant distance was $0.8 \mathrm{~m}$ within rows and 2.5 $\mathrm{m}$ between rows, which were oriented north-south. In the field experiment, water was applied with 2.0 $\mathrm{L} \mathrm{h}^{-1}$ drip emitters, one per vine.

Two irrigation treatments were applied during the season: 
(1) Irrigated vines (defined as FI, full irrigation): Vines were irrigated weekly to keep their stem water potential above $-0.6 \mathrm{MPa}$, established as a threshold for no-water stress conditions [21]. Irrigation treatment started at the pea-sized berry stage (BBCH 74) [22];

(2) stressed vines (defined as NI, no irrigation): Vines were not irrigated unless they displayed the values of stem water potential of $-1.4 \mathrm{MPa}$, in order to avoid excessive stress [21].

Furthermore, two ABA sub-treatments were set up:

(1) Exogenous ABA (defined as A, abscisic acid) applied at veraison (50\% color berry change, $\mathrm{BBCH} 83)$;

(2) no exogenous ABA applied (defined as C, Control).

The experiment was thus conducted with a fully randomized block design with three replicates of nine vines for a total of four treatments:

(a) FIA: Full irrigation (FI) with ABA applied (A);

(b) FIC: Full irrigation (FI) without ABA applied (C);

(c) NIA: No irrigation (NI) with ABA applied (A);

(d) NIC: No irrigation (NI) without ABA applied (C).

Commercial ABA (ProTone SL) containing S-abscisic acid at a 10\% concentration, and supplied by Valent BioScience Corporation ${ }^{\circledR}$, Libertyville, IL, USA, was sprayed at the recommended label rate of 4 $\mathrm{mL} \mathrm{L}^{-1}$ on clusters at $\mathrm{BBCH}$ 83. The application was repeat six days later, as suggested by Ferrara et al. [23] using a simple shoulder pump. ProTone SL was applied in the early evening. Irrigation was supplied in the early evening by a drip system with drippers positioned at $40 \mathrm{~cm}$ over the soil, spaced $40 \mathrm{~cm}$ apart, each able to provide a flow rate of $2.0 \mathrm{~L} \mathrm{~h}^{-1}$.

Vine water status was evaluated with the pressure chamber. For each cultivar and sampling date, two fully mature and sun-exposed leaves were selected from two vines for each replicate in both FI (FIA + FIC) and NI (NIA + NIC) treatments in order to measure the stem water potential (Istem). These leaves were usually selected in the median part of the shoot. Stem water potential was monitored every 10 days during the season starting from day of the year (DOY) 180 and 170 in 2016 and 2017, respectively, using a Pump Up pressure chamber, PMS Instruments Company, Albany, OR, USA. Leaves were covered with aluminium foil and coated with a plastic bag for one hour before each measurement was taken at solar noon.

\subsection{Leaf Area}

Leaf surface was determined at BBCH 88 using a planimeter, LI-3100C Area Meter, LI-COR Biosciences, Lincoln, NB, USA. Two randomly selected shoots were excised from two vines in both irrigation treatments FI (FIA + FIC) and NI (NIA + NIC) and the number of main leaves, secondary shoots and leaves of secondary shoots was measured and recorded. Total leaf area (TLA) was determined as the sum of main leaf area (MLA) and secondary leaf area (SLA).

\subsection{Must Composition}

Starting from veraison (BBCH 81), every 20 days and for a total of four sampling dates, 300 berries were randomly taken for each treatment and replicate in order to measure total soluble solids (TSS, Brix), titratable acidity (TA, $\mathrm{g}$ tartaric acid $\left.\mathrm{L}^{-1}\right), \mathrm{pH}$, total phenolicics $\left(\mathrm{mg} \mathrm{L}^{-1}\right)$ and total anthocyanins $\left(\mathrm{mg} \mathrm{L}^{-1}\right)$. Due to a faster ripening process occurring in season 2017, the last two samplings were performed every 15 days. Total soluble solids were determined with a handheld refractometer, $\mathrm{pH}$ with a pHmeter, and TA by titration. Total phenolics and anthocyanins were determined, after peeling the frozen berries, using the methodology proposed by Di Stefano and Cravero [24], with ultraviolet absorption measured at $700 \mathrm{~nm}$ and $520 \mathrm{~nm}$.

\subsection{Yield, Yield Components and Pruning Weight}

Grapes from all treatments were harvested on the same date. At harvest, vine yield and its composition were recorded by weighing yield produced and counting the number of clusters per vine. 
To define the average berry weight, 200 berries, randomly picked from 10 clusters randomly chosen for each replicate, were weighed. During winter, pruning weight $(\mathrm{PW})$ was determined on nine vines per each treatmentby weighing the cane prunings removed at winter pruning on each individual vine.

\subsection{Statistical Analysis}

Statistical data analysis was performed using SPSS16.0 (SPSS Corp., Chicago, IL, USA) for analysis of variance (ANOVA). Least significant difference (LSD) test was applied for mean separation. Different letters in tables and figures represent significant differences for P-value $<0.05$, whereas the symbol ns indicates no significant difference among treatments.

\section{Results}

\subsection{Meteorological Conditions}

The meteorological trend was different over the two experimental years (Table 1). The first year (2016) was characterized by high rainfall and humidity from January to late spring, while 2017 was one of the hottest and driest years of the last 30 years in the Mediterranean area. A higher value of evapotranspiration (ET0) was observed considering the July-August period as well as the entire year. The lower rainfall observed in 2017, associated with a higher evapotranspiration demand due to higher temperatures, highlight the severe conditions reached during the entire growing season.

Table 1. Main climatic factors recorded during 2016, 2017 and the 30-year period 1980-2010 in Sassari (Sardinia, Italy).

\begin{tabular}{cccc}
\hline Parameter & \multicolumn{3}{c}{ Year } \\
\hline Total rainfall $(\mathrm{mm})$ & $\mathbf{2 0 1 6}$ & $\mathbf{2 0 1 7}$ & $\mathbf{1 9 8 0 - 2 0 1 0}$ \\
\hline Rainfall January-March $(\mathrm{mm})$ & 497.6 & 369.4 & 485.5 \\
Rainfall April-June $(\mathrm{mm})$ & 201.4 & 111.6 & 141.0 \\
Rainfall July-August $(\mathrm{mm})$ & 41.0 & 48.3 & 117.7 \\
Mean of daily min. temp. January-February $\left({ }^{\circ} \mathrm{C}\right)$ & 37.0 & 0.4 & 16.9 \\
Mean of daily max. temp. April-May $\left({ }^{\circ} \mathrm{C}\right)$ & 7.4 & 6.9 & 5.0 \\
Mean of daily med. temp. July-August $\left({ }^{\circ} \mathrm{C}\right)$ & 20.5 & 22.9 & 24.9 \\
Mean of daily max. temp. July-August $\left({ }^{\circ} \mathrm{C}\right)$ & 23.1 & 27.2 & 30.7 \\
ETO year (mm) & 28.8 & 33.9 & Not available \\
ETO June-Aug $(\mathrm{mm})$ & 1000.9 & 1296.2 & Not available \\
\hline
\end{tabular}

\subsection{Vine Water Status, Vegetative Growth and Yield}

In 2016 and 2017, stem water potential was measured 11 and 12 times, respectively (Figure 1). In correspondence with the natural reduction of water resources in the soil, stem water potential values decreased in response to soil water depletion. Statistical differences between FI (FIA + FIC) and NI (NIA + NIC) treatments were observed within cultivars.

The stem water potentials of -0.6 and $-1.4 \mathrm{MPa}$, used as thresholds for irrigation scheduling in FI and NI, respectively, revealed an important difference in cultivar behaviour. In 'Merlot' (Figure 1A,D) and 'Sangiovese' (Figure 1B,E), stem water potential in FI vines was often detected below $-0.6 \mathrm{MPa}$. While the average value of stem water potential in 'Merlot' was $-0.8 \mathrm{MPa}$ throughout both seasons, the values recorded for 'Sangiovese' were -0.8 and $-0.9 \mathrm{MPa}$ in 2016 and 2017, respectively. On the other hand, vines subjected to FI treatment were supplied with 1840 and $1940 \mathrm{~m}^{3} \mathrm{ha}^{-1}$ of water in the first and second year, respectively, which turned out to be insufficient to maintain the stem water potential above the threshold value of $-0.6 \mathrm{MPa}$. In NI vines, stem water potential became progressively negative throughout the season and 'Merlot' and 'Sangiovese' reached the threshold of $-1.4 \mathrm{MPa}$ at different times. 
'Merlot A

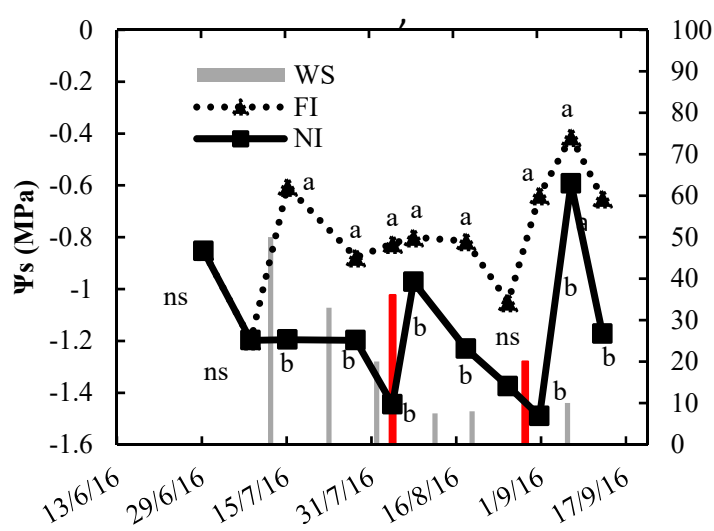

'Sangiovese' B

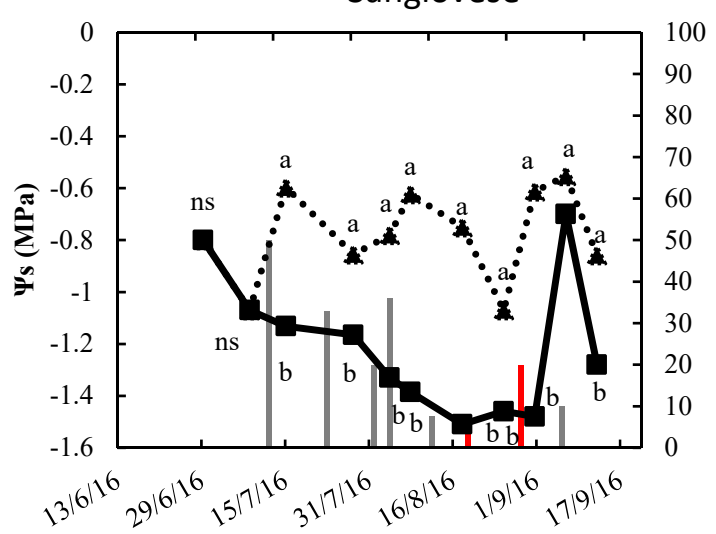

'Cannonau' C

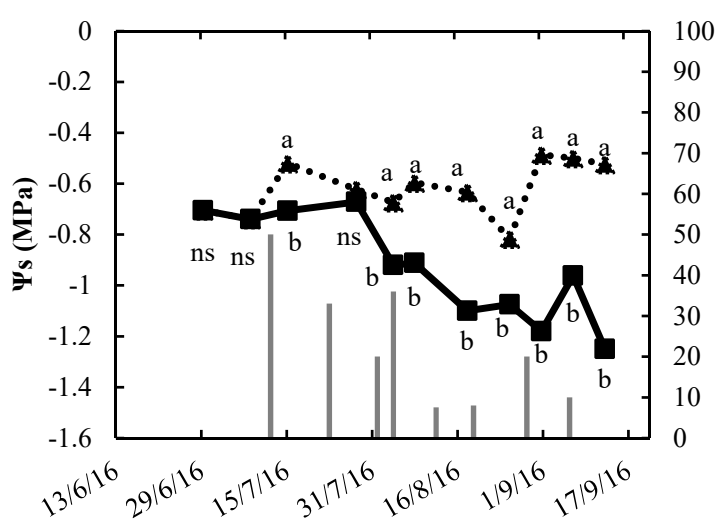

'Merlot D

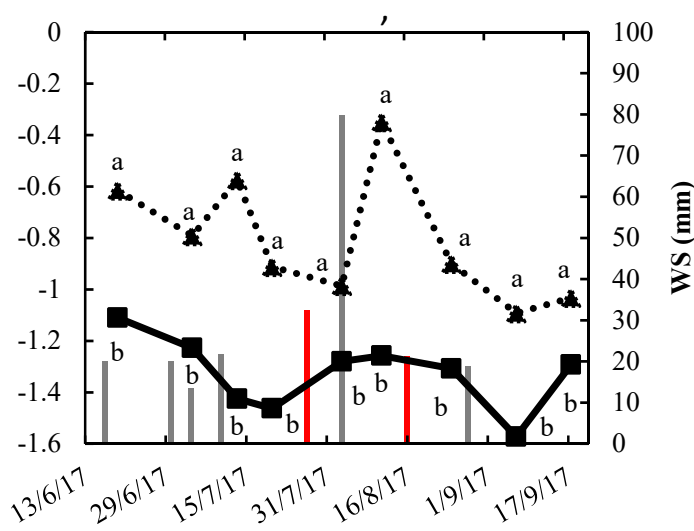

'Sangiovese E

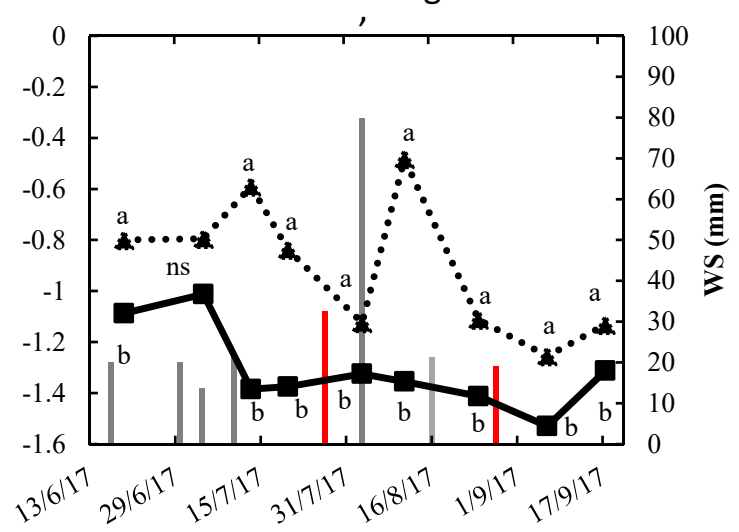

Figure 1. Seasonal patterns in midday stem water potential (YS) in 'Merlot', 'Sangiovese' and 'Cannonau' vines in 2016 (A-C) and 2017 (D-F) subjected to full irrigation (FI) and no irrigation (NI) treatments. WS (histogram) $=$ water supply with irrigation treatment. Gray histograms = full irrigation treatment. Red histograms $=$ no irrigation treatment, only irrigated when plant reached $-1.4 \mathrm{MPa}$ stem water potential.

In 2016 in 'Merlot', 70 and $20 \mathrm{~L}_{\text {vine }}{ }^{-1}$ were supplied on 4 August and 1 September, respectively. On the other hand, the irrigation threshold in 'Sangiovese' was reached later than in 'Merlot' (18 August). However, the amount of water supplied (equal to $16 \mathrm{~L}$ vine ${ }^{-1}$ ) was not able to restore any value above $-1.4 \mathrm{MPa}$, thus another irrigation (40 $\mathrm{L} \mathrm{vine}^{-1}$ dispensed) was necessary. 
In 2017, although the stem water potential trend was similar to the previous season, higher negative values were recorded. Furthermore, 'Merlot' (Figure 1D) and 'Sangiovese' (Figure 1E) simultaneously reached the irrigation threshold value of $-1.4 \mathrm{MPa}$. Both cultivars were irrigated on 27 July with 65 $\mathrm{L}_{\text {vine }}{ }^{-1}$. Subsequently, on 16 August, 'Merlot' was mistakenly irrigated (42 L vine ${ }^{-1}$ ) although the value was higher than -1.4 MPa. In 'Sangiovese', after the first irrigation of the NI treatment, stem water potential showed a slight but constant decrease, reaching once again a value of $-1.4 \mathrm{MPa}$ on 1 September. A second irrigation treatment in NI vines was then applied in 'Sangiovese' ( $30 \mathrm{~L}$ vine $\left.{ }^{-1}\right)$.

'Cannonau' (Figure 1C,F) showed less sensitivity to water stress. The stem water potential was less negative compared to 'Merlot' and 'Sangiovese', and in neither season reached a value above -1.4 $\mathrm{MPa}$, the threshold chosen as the index of severe stress in the NI treatment. In fact, in the driest year (2017), stem water potential showed an average of $-0.7 \mathrm{MPa}$ in the FI treatment.

The main components of the canopy of 'Merlot', 'Sangiovese' and 'Cannonau' are reported in Table 2. Significant differences in the number of shoots per vine were observed only in 'Merlot' during the second experimental year. Significant differences in TLA were observed within each cultivar in 2016. The FI treatment showed significantly higher values in all cultivars than the NI treatment. For 'Merlot', 'Sangiovese' and 'Cannonau' the values of TLA observed in FI and NI treatments were 3.91 and 1.98, 5.84 and 2.56, 6.85 and $3.33 \mathrm{~m}^{2}$, respectively. Total leaf area differed between seasons. In 2017, both 'Merlot' and 'Sangiovese' showed higher values of TLA in FI ( $2.84 \mathrm{~m}^{2}$ and $1.79 \mathrm{~m}^{2}$, respectively) compared to that in NI $\left(2.21 \mathrm{~m}^{2}\right.$ and $1.29 \mathrm{~m}^{2}$, respectively). In contrast, in 'Cannonau', TLA was slightly higher in NI compared to FI $\left(3.63 \mathrm{~m}^{2}\right.$ versus $\left.3.54 \mathrm{~m}^{2}\right)$, but this difference was not significant when subjected to statistical analysis.

Table 2. Main components of canopy in 'Merlot', 'Sangiovese' and 'Cannonau' vines subjected to full irrigation (FI) or no irrigation (NI). MLA = main leaf area; SLA =secondary leaf area; TLA = total leaf area; $\mathrm{PW}=$ pruning weight. Means within column/component followed by different letters were significantly different at $P \leq 0.05$ using T-test.

\begin{tabular}{|c|c|c|c|c|c|c|c|}
\hline \multirow[t]{2}{*}{ Cultivar } & \multirow[t]{2}{*}{ Year } & \multirow[t]{2}{*}{ Treatment } & \multicolumn{5}{|c|}{ Canopy Components } \\
\hline & & & Shoot/Vine & $\operatorname{MLA}\left(\mathrm{m}^{2}\right)$ & $\operatorname{SLA}\left(\mathrm{m}^{2}\right)$ & $\operatorname{TLA}\left(\mathrm{m}^{2}\right)$ & PW (Kg) \\
\hline \multirow{4}{*}{ 'Merlot' } & \multirow{2}{*}{2016} & FI & $8.00 \mathrm{a}$ & $2.09 a$ & $1.81 \mathrm{a}$ & $3.91 \mathrm{a}$ & $0.82 \mathrm{a}$ \\
\hline & & NI & $7.83 a$ & $1.45 b$ & $0.53 a$ & $1.98 \mathrm{~b}$ & $0.66 \mathrm{~b}$ \\
\hline & \multirow{2}{*}{2017} & FI & $7.1 \mathrm{a}$ & $1.75 \mathrm{a}$ & $1.09 \mathrm{a}$ & $2.84 \mathrm{a}$ & $0.65 a$ \\
\hline & & NI & $7.8 \mathrm{~b}$ & $1.57 \mathrm{a}$ & $0.60 \mathrm{a}$ & $2.21 \mathrm{a}$ & $0.55 b$ \\
\hline \multirow{4}{*}{ 'Sangiovese' } & \multirow{2}{*}{2016} & FI & $8.91 \mathrm{a}$ & $2.99 a$ & $2.48 \mathrm{a}$ & $5.84 \mathrm{a}$ & $1.01 \mathrm{a}$ \\
\hline & & NI & $9.08 \mathrm{a}$ & $1.70 \mathrm{~b}$ & $0.86 b$ & $2.56 \mathrm{~b}$ & $0.65 b$ \\
\hline & \multirow{2}{*}{2017} & FI & $7.20 \mathrm{a}$ & $1.05 \mathrm{a}$ & $0.74 a$ & $1.79 \mathrm{a}$ & $0.64 a$ \\
\hline & & NI & $6.35 a$ & $0.73 b$ & $0.56 a$ & $1.29 a$ & $0.55 a$ \\
\hline \multirow{4}{*}{ ‘Cannonau' } & \multirow{2}{*}{2016} & FI & $12.91 \mathrm{a}$ & $3.28 \mathrm{a}$ & $3.56 \mathrm{~b}$ & $6.85 a$ & $1.10 \mathrm{a}$ \\
\hline & & NI & $12.83 a$ & $2.41 b$ & $0.91 \mathrm{a}$ & $3.33 b$ & $0.84 b$ \\
\hline & \multirow{2}{*}{2017} & FI & $11.64 a$ & $1.75 \mathrm{a}$ & $1.78 \mathrm{a}$ & $3.54 a$ & $0.66 a$ \\
\hline & & NI & $11.42 \mathrm{a}$ & $1.78 \mathrm{a}$ & $1.64 a$ & $3.63 a$ & $0.64 a$ \\
\hline
\end{tabular}

In 'Merlot' and 'Sangiovese', MLA was higher than SLA both in FI and NI treatments in both experimental seasons. 'Cannonau' exhibited different canopy development, SLA was higher than MLA in FI, reaching values of 3.56 and $1.78 \mathrm{~m}^{2}$ in 2016 and 2017, respectively. In contrast, in NI, MLA was higher than SLA in both 2016 and 2017, as the MLA reached a value of 2.41 and $1.78 \mathrm{~m}^{2}$, respectively.

Comparing the two seasons and both treatments, 'Cannonau' showed higher PW values than 'Sangiovese' and 'Merlot'. In the first season, FI treatment exhibited a significantly greater pruning weight than NI treatment in all tested cultivars. In the second season, in 'Merlot', the pruning weight recorded in FI treatment appeared significantly higher than in NI treatment whereas no statistical differences were detected in 'Sangiovese' and 'Cannonau'. 
Table 3 shows the effect of irrigation and exogenous ABA treatment on yield and the yield components of the three cultivars under observation. Significant differences in yield were observed in all cultivars and seasons except for 'Cannonau' in 2016. In 'Merlot', in the first experimental year, FIA treatment $\left(\mathrm{FI}+\mathrm{ABA}\right.$ ) reached the highest yield with $2.42 \mathrm{~kg}$ vine $^{-1}$, whereas FIC (FI - ABA), NIA $(\mathrm{NI}+\mathrm{ABA})$ and NIC (NI - ABA) yielded 1.96, 1.85 and $1.57 \mathrm{~kg}$ vine $^{-1}$, respectively. In 2017, the yield recorded at harvest in full irrigation treatments FIA and FIC, with 2.0 and $2.23 \mathrm{~kg} \mathrm{vine}^{-1}$, respectively, was significantly different when compared with NIA and NIC, with production per vine of 1.20 and $1.10 \mathrm{~kg}$, respectively.

Table 3. Effect of irrigation and exogenous abscisic acid (ABA) treatments on yield and yield components in 'Merlot', 'Sangiovese' and 'Cannonau'. FIA = full irrigation $(+)$ ABA; FIC = full irrigation (-) $\mathrm{ABA} ; \mathrm{NIA}=$ no irrigation $(+) \mathrm{ABA}$; NIC $=$ no irrigation $(-)$ ABA. Means within column/(cultivar season) followed by different letters were significantly different at $P \leq 0.05$ using the LSD test. ns $=$ not significant.

\begin{tabular}{|c|c|c|c|c|c|c|}
\hline Cultivar & Seasons & Treatment & Yield (kg Vine $\left.{ }^{-1}\right)$ & Cluster Vines $^{-1}\left(n^{\circ}\right)$ & Cluster Weight (g) & Berry Weight (g) \\
\hline \multirow[t]{10}{*}{ 'Merlot' } & 2016 & FIA & $2.42 \mathrm{a}$ & 14.50 & $167.56 \mathrm{a}$ & $1.88 \mathrm{a}$ \\
\hline & & FIC & $1.96 \mathrm{~b}$ & 14.38 & $137.45 \mathrm{~b}$ & $1.78 \mathrm{a}$ \\
\hline & & NIA & $1.85 \mathrm{~b}$ & 16.00 & $116.12 \mathrm{bc}$ & $1.48 \mathrm{~b}$ \\
\hline & & NIC & $1.57 \mathrm{~b}$ & 15.38 & $99.34 \mathrm{c}$ & $1.20 \mathrm{~b}$ \\
\hline & & $P$-value (T) & 0.002 & ns & 0.0001 & 0.012 \\
\hline & 2017 & FIA & $2.00 \mathrm{a}$ & 13.6 & $151.9 \mathrm{a}$ & $1.57 \mathrm{a}$ \\
\hline & & FIC & $2.23 \mathrm{a}$ & 14.00 & $157.74 \mathrm{a}$ & $1.50 \mathrm{a}$ \\
\hline & & NIA & $1.20 \mathrm{~b}$ & 12.5 & $105.13 \mathrm{~b}$ & $1.00 \mathrm{~b}$ \\
\hline & & NIC & $1.10 \mathrm{~b}$ & 11.5 & $105.92 \mathrm{~b}$ & $0.90 \mathrm{~b}$ \\
\hline & & $P$-value (T) & 0.000 & ns & 0.000 & 0.03 \\
\hline \multirow[t]{10}{*}{ 'Sangiovese' } & 2016 & FIA & $4.11 \mathrm{a}$ & 9.5 & 328.33 a & 2.44 \\
\hline & & FIC & $2.84 a b$ & 9.65 & $234.23 \mathrm{ab}$ & 2.22 \\
\hline & & NIA & $3.16 \mathrm{a}$ & 8.66 & $281.68 \mathrm{a}$ & 2.26 \\
\hline & & NIC & $2.16 \mathrm{~b}$ & 8.85 & $216.10 \mathrm{~b}$ & 1.85 \\
\hline & & $P$-value (T) & 0.016 & ns & 0.002 & ns \\
\hline & 2017 & FIA & $3.21 \mathrm{a}$ & 13.93 & 239.67 & $2.32 \mathrm{a}$ \\
\hline & & FIC & $2.74 \mathrm{a}$ & 12.33 & 231.00 & $2.12 \mathrm{a}$ \\
\hline & & NIA & $1.92 \mathrm{~b}$ & 10.26 & 211.20 & $1.46 \mathrm{~b}$ \\
\hline & & NIC & $1.96 \mathrm{~b}$ & 11.13 & 189 & $1.27 \mathrm{~b}$ \\
\hline & & $P$-value (T) & 0.003 & ns & ns & 0.006 \\
\hline \multirow[t]{10}{*}{ 'Cannonau' } & 2016 & FIA & 1.41 & $10.5 \mathrm{bc}$ & $136.40 \mathrm{a}$ & $2.81 \mathrm{a}$ \\
\hline & & FIC & 1.45 & $9.38 \mathrm{c}$ & $166.91 \mathrm{a}$ & $2.82 \mathrm{a}$ \\
\hline & & NIA & 1.59 & $12.92 \mathrm{a}$ & $133.85 \mathrm{~b}$ & $2.49 \mathrm{ab}$ \\
\hline & & NIC & 1.61 & $12.19 \mathrm{ab}$ & $129.87 \mathrm{~b}$ & $2.27 \mathrm{~b}$ \\
\hline & & $P$-value (T) & ns & 0.015 & 0.028 & 0.025 \\
\hline & 2017 & FIA & $2.59 \mathrm{a}$ & $16.10 \mathrm{ab}$ & 218.78 a & $2.65 \mathrm{a}$ \\
\hline & & FIC & $2.97 \mathrm{a}$ & $18.71 \mathrm{a}$ & $162.70 \mathrm{ab}$ & $2.61 \mathrm{a}$ \\
\hline & & NIA & $1.53 \mathrm{~b}$ & 10.80 c & $160.31 \mathrm{ab}$ & $2.0 \mathrm{~b}$ \\
\hline & & NIC & $1.88 \mathrm{~b}$ & $12.64 \mathrm{bc}$ & $148.86 \mathrm{~b}$ & $1.80 \mathrm{~b}$ \\
\hline & & $P$-value (T) & 0.002 & 0.02 & 0.01 & 0.02 \\
\hline
\end{tabular}

Significant differences in yield were also observed for cv. 'Sangiovese'. In 2016, the highest yield was reached by FIA treatment with $4.11 \mathrm{~kg}$ vine $^{-1}$, which was not significantly different than FIC and NIA (2.84 and $3.16 \mathrm{~kg}_{\text {vine }}{ }^{-1}$, respectively). The lowest yield $\left(2.16 \mathrm{~kg}_{\text {vine }}{ }^{-1}\right)$ was in the NIC treatment. In the following season, as observed in 'Merlot', both irrigation treatments FIA and FIC (3.21 and 2.74 $\mathrm{kg}_{\text {vine }}{ }^{-1}$ of yield, respectively) were significantly higher than both no irrigation treatments NIA and NIC (1.92 and $1.96 \mathrm{~kg} v$ vine $^{-1}$, respectively). Finally, in cv. 'Cannonau', no significant differences were observed in 2016 among the different imposed treatments, whereas the observations in 2017 were in agreement with those in 'Merlot' and 'Sangiovese'. FIA and FIC treatments, with a yield of 2.59 and $2.97 \mathrm{~kg} \mathrm{vine}^{-1}$, showed higher values than NIA and NIC, which yielded 1.53 and $1.88 \mathrm{~kg}$ vine $\mathrm{e}^{-1}$, respectively. With regards to cluster weight, significant differences were observed among treatments, cultivars and years, except for cv. 'Sangiovese' in the second season. Overall, both full irrigation treatments (FIA and FIC) showed higher cluster and berry weights than treatments without irrigation (NIA and NIC). 


\subsection{Grape Berry Composition in Response to Water Deficit and Abscisic Acid Application}

\subsection{1. 'Merlot'}

In the first season, TSS and total acidity (TA) ripening dynamics were quite similar among treatments (Figure 2A,B). No significant differences were observed in either TSS or TA at harvest, with values of 22 and 23 Brix for FIC and NIA, respectively, and 4.2 and $3.6 \mathrm{~g} \mathrm{~L}^{-1}$ for FIA and FIC, respectively.
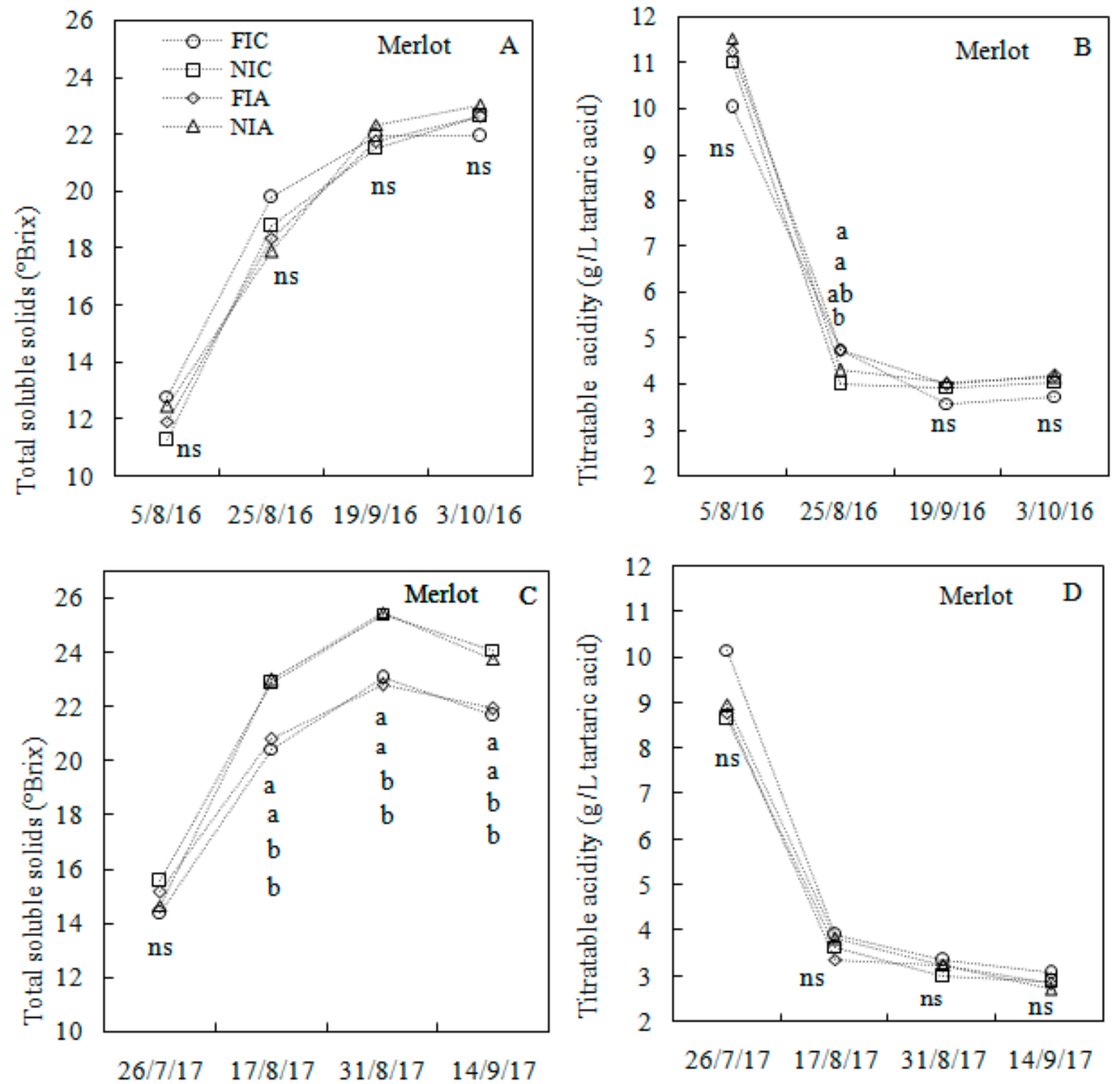

Figure 2. Seasonal variations of grape total soluble solids in 2016 (A) and 2017 (C) and titratable acidity in 2016 (B) and 2017 (D) in cv. 'Merlot'. FIA = full irrigation (+) ABA; FIC = full irrigation (-) ABA; $\mathrm{NIA}=$ no irrigation $(+) \mathrm{ABA} ; \mathrm{NIC}=$ no irrigation $(-) \mathrm{ABA}$. The different letters indicate statistical significance at $P \leq 0.05$ using the LSD test. ns = not significant.

In 2017, significant differences in TSS (Figure 2C) were observed 20 days after veraison and until harvest. The evolution in the TSS accumulation was characterized by two well-defined trends. Both treatments not subjected to irrigation (NIA and NIC) showed a significantly higher accumulation rate than treatments with water supply (FIA and FIC). At harvest, sugar concentration in NIC and NIA were 24.99 and $23.73^{\circ}$ Brix, respectively, whereas in FIA and FIC, TSS was 21.93 and $21.66{ }^{\circ}$ Brix, respectively. No significant differences in TA were observed among treatments at harvest (Figure 2D), with values 
of 2.71 and 3.06 in FIC and FIA, respectively. Comparing the seasons, higher sugar concentrations and lower acidic content were observed in 2017 than 2016.

In 2016, no significant differences were observed for total anthocyanins and phenolics (Figure 3A,B). Twenty days after veraison (25 August 2016), all treatments reached the maximum concentration of the total anthocyanins accumulated in the grape (Figure 3A). The highest value was observed in FIA treatment $\left(297 \mathrm{mg} \mathrm{L}^{-1}\right)$, followed by NIA, FIC and NIC treatments, which showed values of 271,257 and $224 \mathrm{mg} \mathrm{L}^{-1}$, respectively. Anthocyanins decreased abruptly after reaching the seasonal peak on 25 August 2016. No significant differences were observed at harvest.
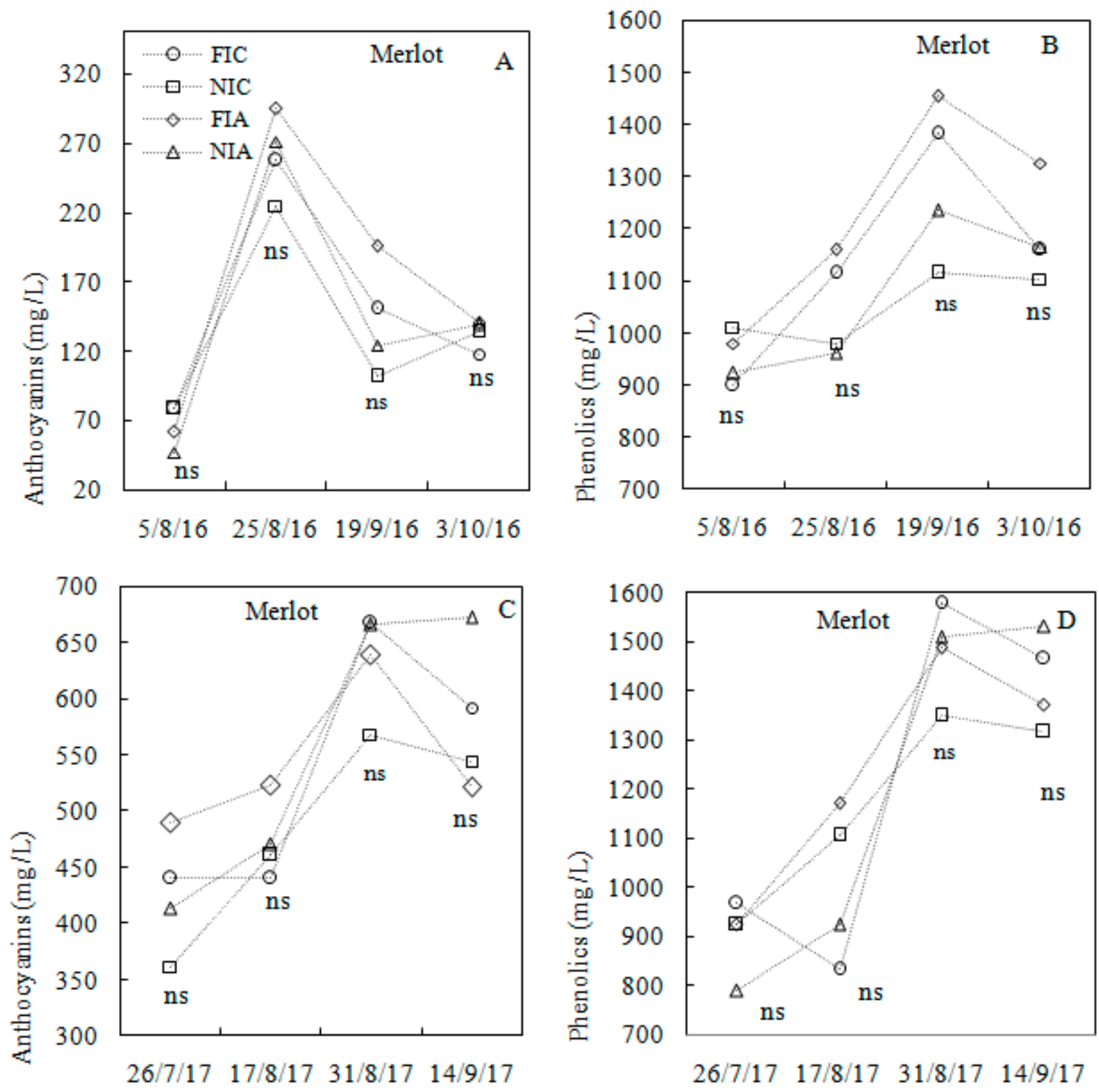

Figure 3. Seasonal variations of grape total Anthocyanins in 2016 (A) and 2017 (C) and Phenolics in 2016 (B) and 2017 (D) in cv. 'Merlot'. FIA = full irrigation (+) ABA; FIC = full irrigation (-) ABA; NIA $=$ no irrigation $(+)$ ABA NIC $=$ no irrigation $(-)$ ABA. ns indicates no significant differences at $P \leq 0.05$.

Starting from veraison, on 5 August 2016, total phenolicics in FIA and FIC showed a constant increase over time reaching the maximum values on 19 September 2016 (Figure 3B). The highest value was reached by FIA treatment $\left(1454 \mathrm{mg} \mathrm{L}^{-1}\right)$, followed by FIC treatment $\left(1381 \mathrm{mg} \mathrm{L}^{-1}\right)$. Subsequently, total phenolicics in FIA and FIC decreased until harvest. NIA and NIC treatments were characterized by the lowest accumulation rates but also showed a limited decrease in total phenolicics after the peak 
occurred on 19 September 2016. At harvest, no significant differences were observed among treatments in the first season.

During the following season, all treatments reached the highest anthocyanin content on 31 August 2017 (Figure 3C). On that date, anthocyanin values were equal to 667, 666, 639 and $568 \mathrm{mg} \mathrm{L}^{-1}$ on FIC, NIA, FIA and NIC, respectively. After reaching the peak, total anthocyanins started to decrease in all treatments, except for NIA. No significant differences were observed at harvest with values of 672, 591, 544 and 520 for NIA, FIC, NIC and FIA, respectively.

The evolution of the total phenolicic concentration over time turned out to be quite similar to total anthocyanin dynamics (Figure 3D). The peak of polyphenols was observed on 31 August 2017, simultaneously with anthocyanins. On that date, total polyphenols were equal to 1575, 1508, 1485 and $1348 \mathrm{mg} \mathrm{L}^{-1}$, for FIC, NIA, FIA and NIC treatments, respectively. Subsequently, total phenolics progressively decreased, except for NIA treatment. Treatments subjected to full irrigation (FIC and FIA) showing a greater decrease. No significant differences were observed at harvest, in which total polyphenols ranged from 1315 to $1530 \mathrm{mg} \mathrm{L}^{-1}$ in NIA and NIC treatments, respectively.

\subsection{2. 'Sangiovese'}

In 2016, no significant differences among treatments were observed with respect to TSS (Figure 4A). The average values were 21.93 and 21.53 Brixin NIC and FIA treatments, respectively. TSS dynamics showed a steep accumulation rate in the twenty days after veraison, afterwards the accumulation rate decreased. Total acidity showed significant differences among treatments at harvest (Figure 4B). A higher value of TA was observed in NIC and NIA treatments, with values equal to 5.12 and $5.05 \mathrm{~g} \mathrm{~L}^{-1}$, respectively, whereas lower values of 4.62 and $4.55 \mathrm{~g} \mathrm{~L}^{-1}$ were observed in FIA and FIC, respectively. In 2017, both treatments not subjected to irrigation (NIA and NIC) showed higher TSS values compared to FIA and FIC treatments (Figure 4C). Significant differences were observed on the third date of sampling, on 29 August. On that date, the highest value was observed in the NIA treatment, followed by NIC, FIA and FIC, with TSS values 24.2, 23.0, 22.55 and 22.33 Brix, respectively. At harvest, treatments showed the same ranking, although no significant differences were detected. In relation to TA (Figure 4D), significant differences among treatments were observed on the third sampling date on 29 August, in which NIA reached a higher value than NIC, FIA and FIC. Once again, no significant differences were observed at harvest.

In 2016, no significant differences were observed for both total anthocyanins and polyphenols (Figure 5A,B). Total anthocyanins showed the maximum values twenty days after veraison. A higher value was observed in NIC, followed by FIC, FIA and NIA with 216, 187, 173 and $156 \mathrm{mg} \mathrm{L}^{-1}$, respectively. At harvest, all treatments were 119 and $90 \mathrm{mg} \mathrm{L}^{-1}$ (NIA and FIA treatments, respectively). Total polyphenol accumulation constantly increased throughout the season, reaching the highest value at harvest. Even though differences among treatments were not significantly different on the last sampling date, the highest value was recorded with the FIC treatment, followed by NIA, NIC and FIA treatments.

In the second year of the study, the highest amount of total anthocyanins (Figure 5C) was measured on 29 August. The FIC and FIA treatments showed a quite similar trend, whereas NIA was characterized by a higher anthocyanin accumulation in the first month after veraison, followed by a decrease in the last part of the season. In contrast, NIC treatment exhibited a lower accumulation rate in the first month after veraison, followed by an increase in anthocyanins in the last part of the season. At harvest, significant differences were observed among treatments. A higher value was observed in NIA and NIC treatments, with average values of 543 and $536 \mathrm{mg} \mathrm{L}^{-1}$, respectively, whereas lower values were observed for FIC and FIA treatments, with levels of anthocyanins of 436 and $401 \mathrm{mg}$ $\mathrm{L}^{-1}$ respectively. 

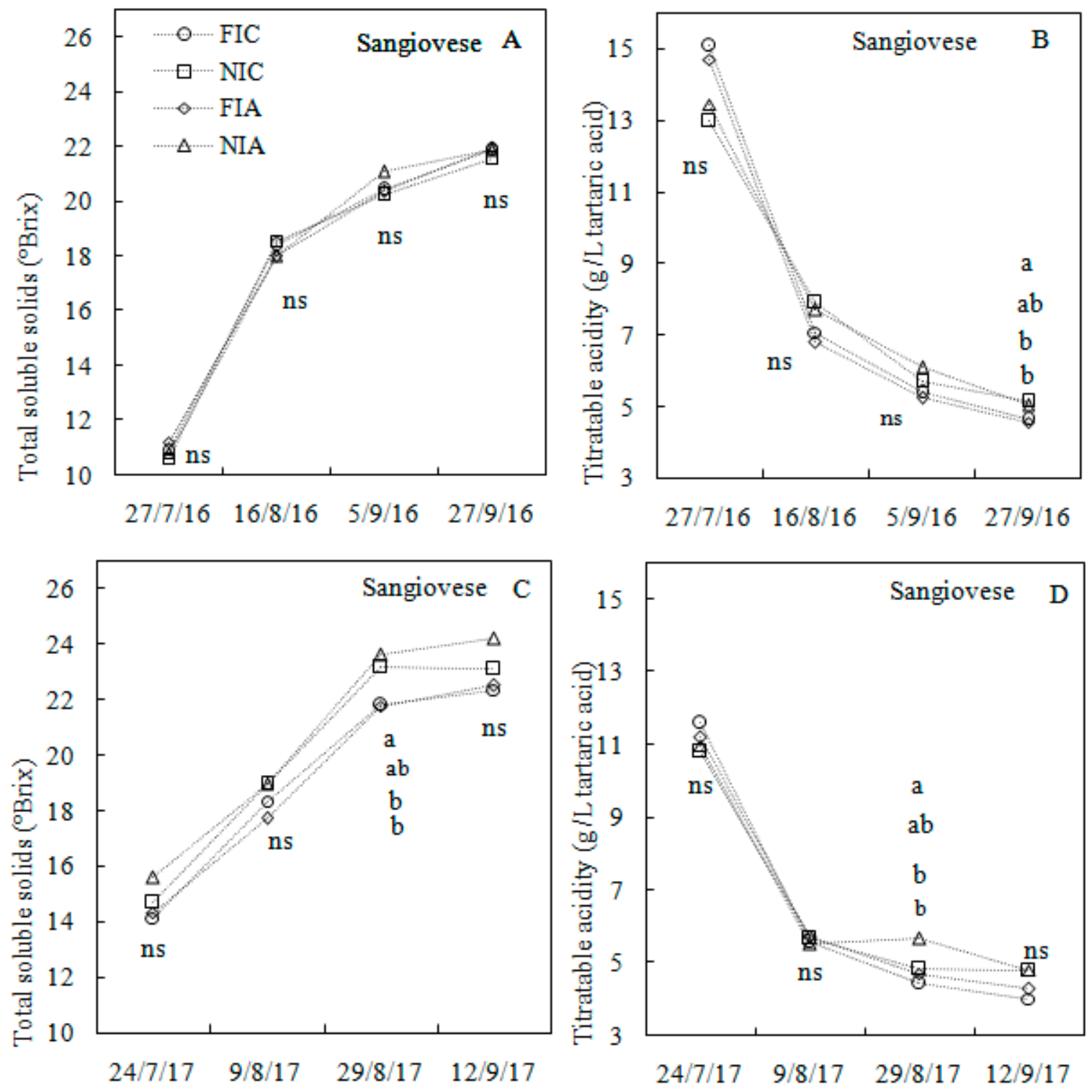

Figure 4. Seasonal variations of grape total soluble solids in 20016 (A) and 2017 (C) and titratable acidity in 2016 (B) and 2017 (D) cv. 'Sangiovese'. FIA = full irrigation (+) ABA; FIC = full irrigation (-) $\mathrm{ABA} ; \mathrm{NIA}=$ no irrigation $(+) \mathrm{ABA} ; \mathrm{NIC}=$ no irrigation $(-)$ ABA. The different letters indicate statistical significance at $P \leq 0.05$ using the LSD test. ns = not significant.

Total phenolicics in 2017 (Figure 5D) showed significant differences during the season and the evolution of total phenolics over time highlighted higher values in both treatments with no irrigation (NIA and NIC) than in irrigation treatments (FIC and FIA).

\subsection{3. 'Cannonau'}

Unlike 'Sangiovese' and 'Merlot', significant differences were observed in TSS in 2016 for 'Cannonau' (Figure 6A). The highest values were found in no irrigation treatments, either with or without ABA applications, reaching $25.9^{\circ} \mathrm{Brix}$ (NIA) and 25.3 (NIC) ${ }^{\circ}$ Brix, whereas lower values were found in the irrigation treatments (24.1 ${ }^{\circ}$ Brix in FIA and $23.6^{\circ}$ Brix in FIC). No significant differences were observed in TA at harvest (Figure 6B), in which the recorded values were 4.82, 4.60, 4.40 and $4.12 \mathrm{~g} \mathrm{~L}^{-1}$ in NIA, FIC, NIC and FIA treatments, respectively. 

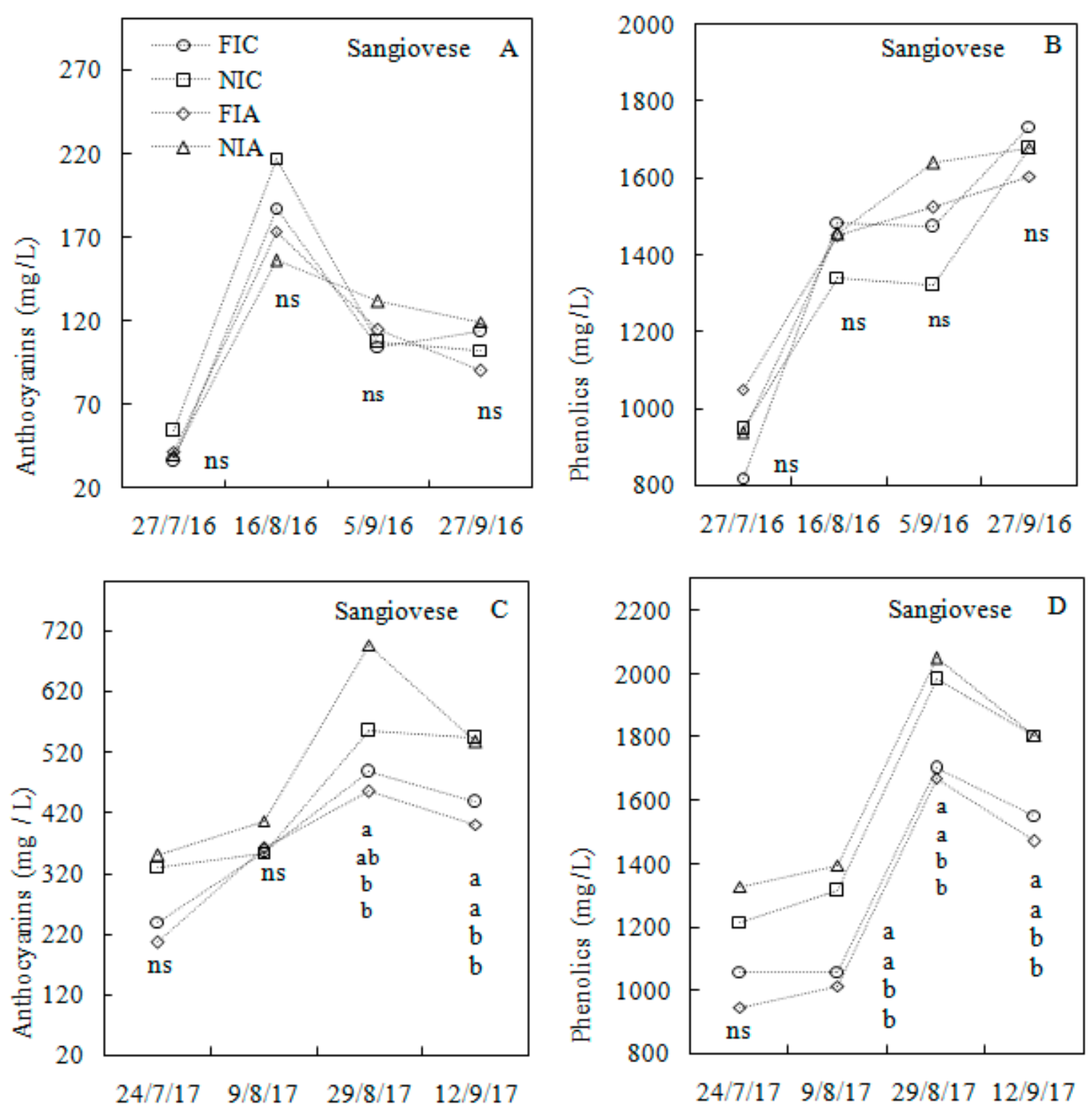

Figure 5. Seasonal variations of grape total anthocyanins in 2016 (A) and 2017 (C) and phenolics in 2016 (B) and 2017 (D) in cv. 'Sangiovese'. FIA = full irrigation (+) ABA; FIC = full irrigation (-) ABA; NIA = no irrigation $(+)$ ABA NIC $=$ no irrigation $(-)$ ABA. The different letters indicate statistical significance at $P \leq 0.05$ using the LSD test. Ns = not significant.

In 2017, the ripening dynamics of TSS (Figure 6C) was quite similar with respect to 2016, although the effect of irrigation was more pronounced than in 2016, and no influence of ABA application was observed. At harvest, TSS in berries reached 25.3 and $25.2^{\circ}$ Brix in NIA and NIC, respectively, whereas TSS were equal to $23.7^{\circ}$ Brix in both FIA and FIC treatments. With regards to TA, as in 2016, no significant differences were observed in 2017 (Figure 6D), although higher values were recorded in irrigation treatments. The average titratable acidity ranged from 3.47 to $3.11 \mathrm{~g} \mathrm{~L}^{-1}$, for FIC and NIA treatments, respectively.

Significant differences were observed in total anthocyanins in both seasons (Figure 7A,C). In 2016, both irrigation treatments showed the highest peak values on the third sample day, with concentrations of 173 and $168 \mathrm{mg} \mathrm{L}^{-1}$ measured in FIA and FIC treatments. At the same time NIA and NIC reached the highest anthocyanin accumulation, exhibiting values of 200 and $190 \mathrm{mg} \mathrm{L}^{-1}$, statistically higher than full irrigation treatments, which then decreased on the last sampling date. At harvest, significant differences between treatments were evident. 

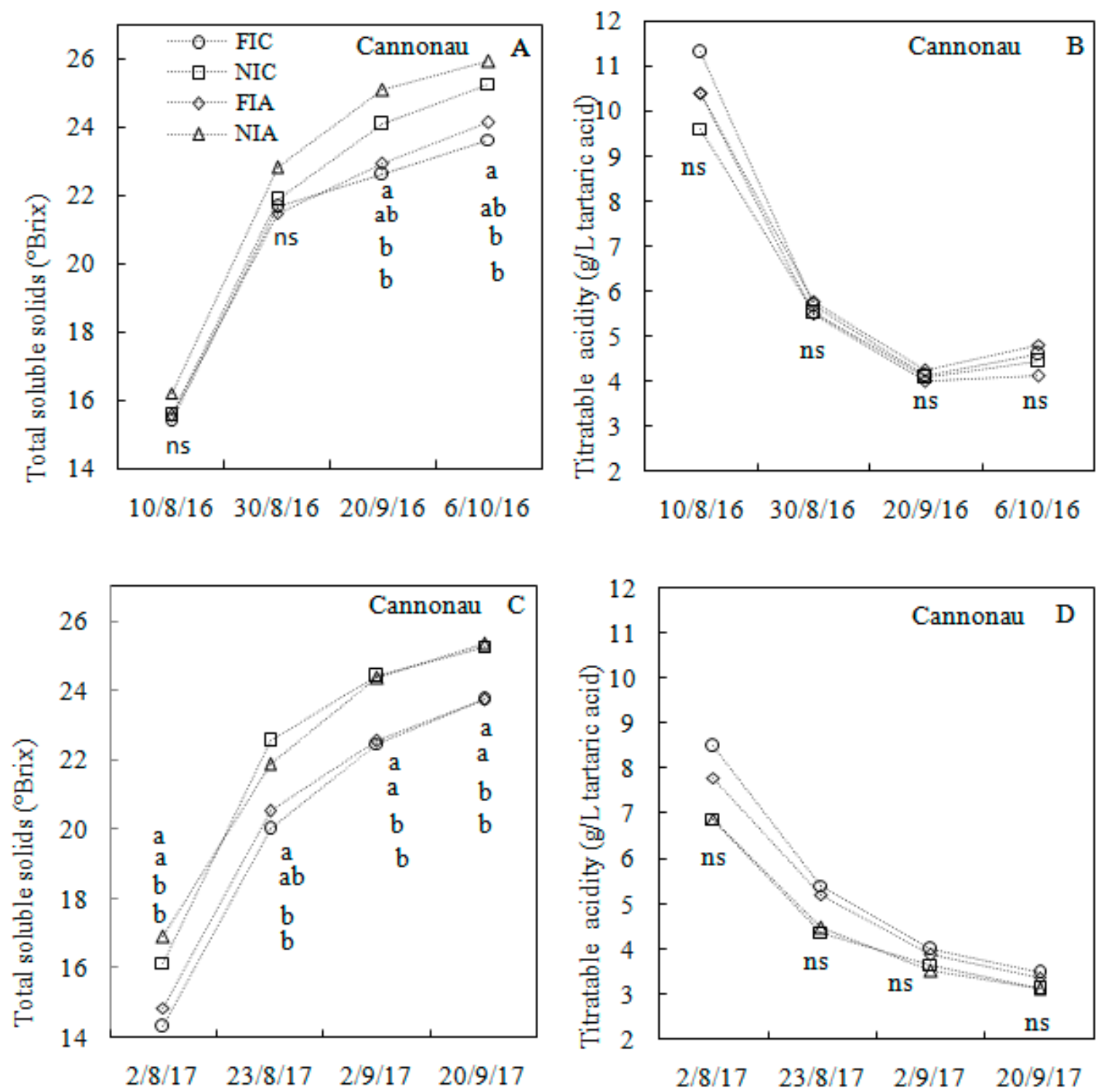

Figure 6. Seasonal variations of grape total soluble solids in 2016 (A) and 2017 (C) and titratable acidity in 2016 (B) and 2017 (D) in cv. 'Cannonau'. FIA = full irrigation (+) ABA; FIC = full irrigation (-) ABA; NIA $=$ no irrigation $(+)$ ABA; NIC $=$ no irrigation $(-)$ ABA. The different letters indicate statistical significance at $P<0.05$ using the LSD test. ns = not significant.

Significant differences were also observed in total phenolics in 2016 (Figure 7B). The highest peak of total phenolics was observed on 20 September. The highest values were detected in NIC and NIA treatments (2788 and $2712 \mathrm{mg} \mathrm{L}^{-1}$, respectively) compared to FIC and FIA (2490 and $2417 \mathrm{mg} \mathrm{L}^{-1}$, respectively). At harvest, the highest value, equal to $2639 \mathrm{mg} \mathrm{L}^{-1}$, was observed in NIA treatment, followed by NIC, FIA and FIC treatments with 2397, 2244 and $2184 \mathrm{mg} \mathrm{L}^{-1}$, respectively. In 2017, significant differences in total anthocyanins were observed at harvest (Figure 7C), in which NIA and NIC treatments showed the highest anthocyanin accumulation (411 and $367 \mathrm{mg} \mathrm{L}^{-1}$, respectively), whereas FIA and FIC treatments showed significantly lower values of 279 and $276 \mathrm{mg} \mathrm{L}^{-1}$, respectively. The highest phenolic peak was observed at harvest in 2017 (Figure 7D). Significant differences were observed, with NIC and NIA treatments showing a higher total phenolic accumulation (1259 and 1249 $\mathrm{mg} \mathrm{L}^{-1}$, respectively) than FIC and FIA treatments (1035 and $961 \mathrm{mg} \mathrm{L}^{-1}$, respectively). 

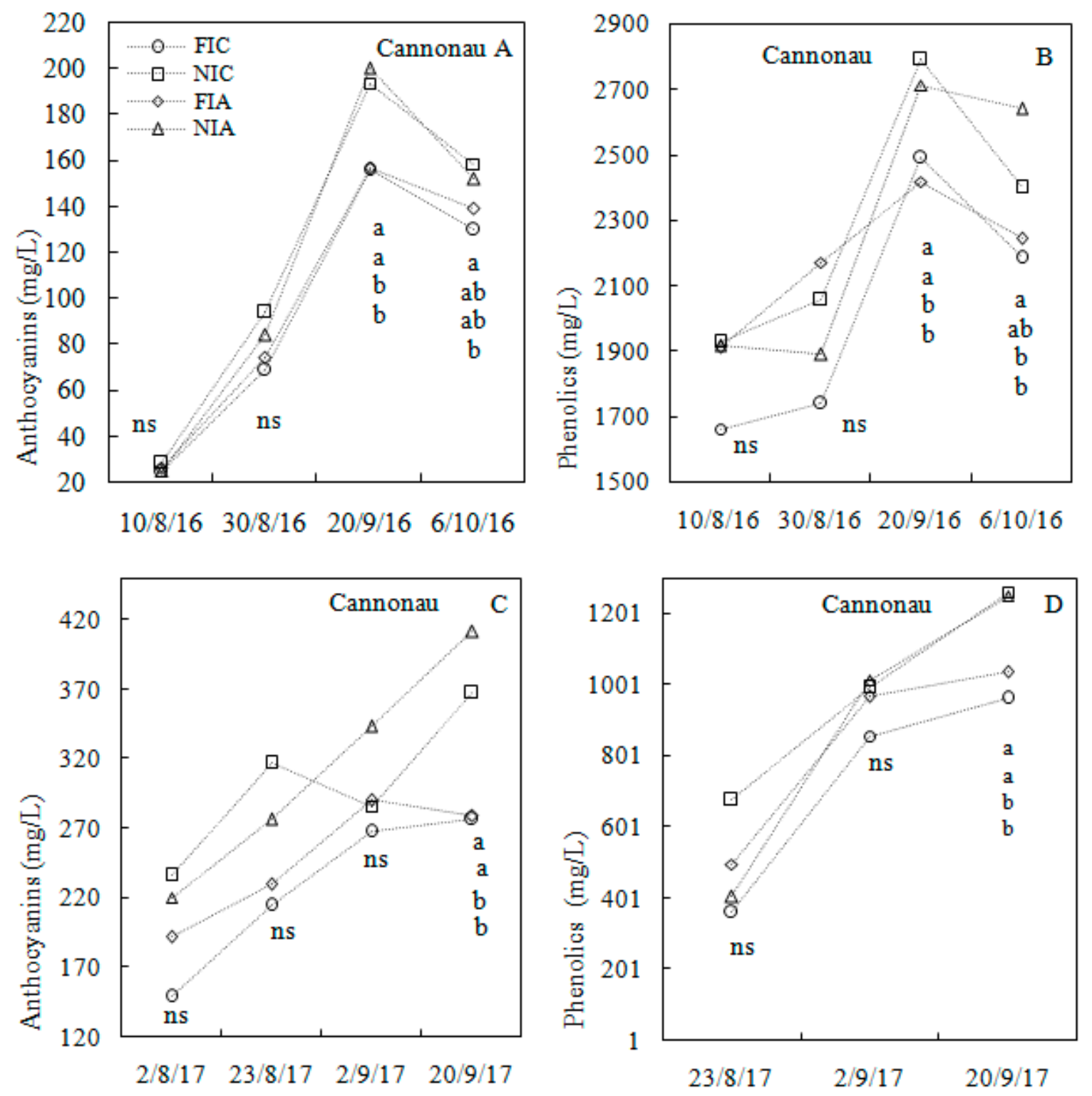

Figure 7. Seasonal variations of grape total anthocyanins in 2016 (A) and 2017 (C) and phenolics in 2016 (B) and 2017 (D) in cv. 'Cannonau'. FIA = full irrigation (+) ABA; FIC = full irrigation (-) ABA; NIA = no irrigation $(+)$ ABA NIC $=$ no irrigation $(-)$ ABA. The different letters indicate statistical significance at $P \leq 0.05$ using the LSD test. ns $=$ not significant.

\section{Discussion}

This physiological and qualitative grape berry comparative study on the three cultivars selected for their anisohydric, ('Merlot' and 'Sangiovese') or isohydric behaviour ('Cannonau'), has highlighted several useful indications for growers and researchers [2,19,25]. 'Merlot', originating in France, is the second cultivar in terms of hectares in grape-growing regions worldwide [26]. 'Sangiovese', which originates in Italy [27], is the most widely grown cultivar of Vitis vinifera L. in Italy. 'Cannonau' (synonym Grenache), native to the Mediterranean area [28], is cultivated in the world's main wine regions and represents the seventh most cultivated cultivar worldwide. In Italy, 'Cannonau' is widely cultivated in Sardinia covering $29 \%$ of the vine-cultivated surfaces and is characterized by its lack of color [29]. 'Merlot' and 'Sangiovese' are grown with excellent results both in hot arid environments and in rainier and cooler areas, while the area of cultivation of the 'Cannonau' is characterized by the dry and little rainy climate of the Mediterranean basin. 
Traditionally, it was generally accepted in viticulture that a water supply in a vineyard was detrimental for wine quality to the extent that, in some areas, watering became a prohibited agronomic practice [30]. However, the dramatically increasing frequency of summers, during which drought periods occur, has shifted attention to the actual need for additional irrigation [31] even in grapevine regions not considered hot and arid. In order to set up appropriate water scheduling in the vineyard, it is important to know the water status of the vines. Among different physiological indicators, stem water potential represents an accurate tool for determining vine water status [32]. Values higher than -0.6 and lower than $-1.4 \mathrm{MPa}$, indicate the conditions of no water stress and severe water stress, respectively [21].

During the experiment, stressed vines of all the three cultivars showed, as expected, a lower stem water potential than irrigated ones. Among the cultivars, in both seasons, 'Cannonau' exhibited a higher value of stem water potential in irrigated and stressed vines, confirming a difference in stomatal sensitivity between genotypes [33]. The different varietal behaviour, observed by evaluating the relationship between the genotype and the water status, has highlighted how these studies represent an important tool for an adequate irrigation management [34]. It is important to highlight that in both years, 'Cannonau' never reached the irrigation threshold of-1.4 MPa in the water stress treatments, adopted as indicator of severe water deficit [21]. As observed by Schultz [8], our experiment confirmed that 'Cannonau' showed a typical isohydric behaviour. The cultivars 'Sangiovese' and 'Merlot' showed similar anisohydric behaviours, characterized by the lowest negative values in stem water potential. Our findings confirm those by Palliotti et al. [33], who stated that the drought response of 'Merlot' and 'Sangiovese' was a near-anisohydric behaviour.

Midday depression of gas exchange is commonly observed in plants, in which stomatal conductance represents a key mechanism in response to water stress [2,9], leading to the prevention of a critical decrease in leaf water potential. It is acknowledged that the timing and the intensity of the response to soil and atmospheric water deficits, namely stomatal control, depend greatly on the genotype [2]. A hypothesis to test is to verify that 'Cannonau', under water restriction conditions, could have a greater control on stomatal conductance than 'Merlot' or 'Sangiovese'.

It is also well known that water stress affects berry chemical composition through two main mechanisms: A "concentration effect" through a berry size reduction that increases the skin to pulp ratio [4] and enhanced biosynthesis through the upregulation of related genes [35]. However, depending on the applied water stress level, a contradictory behaviour among cultivars has been reported in literature. This can be due to different environmental conditions and the application of various agronomic techniques. Herrera et al. [6] found that total soluble solids ( ${ }^{\circ}$ Brix) were reduced by water deficits in 'Merlot' due to a lower photosynthetic rate induced by water scarcity in the soil. In contrast, Salon et al. [36] and Girona et al. [37] stated that a significant difference was observed in 'Pinot Noir' and 'Bobal' when a severe water stress was applied. Moreover, in 'Merlot', Bucchetti et al. [38] reported a positive effect of water stress on anthocyanin concentration, whereas Merli et al. [39], in 'Sangiovese', stated that total anthocyanins and phenolics were neither affected in vines under well-watered conditions or subjected to progressive post-veraison water stress. Furthermore, must composition could be influenced by genetic factors. In a recent study conducted by Merli et al. [7], the authors suggested that grafting the same cultivars onto different rootstocks may trigger differential gene regulation under water stress and higher temperatures leading to a different must composition. It is clear that varietal responses are the result of specific interactions between environmental, agronomic and genetic factors.

In our study, the effect of water stress on sugar accumulation was detected in 'Sangiovese' and 'Merlot' in 2017, in which higher concentrations of soluble solids were observed in vines subjected to water restrictions because of 'concentration effects', while in 'Cannonau', a significant difference in sugar accumulation among treatments was observed in both years.

As observed for primary metabolites, water stress can increase the concentration of secondary metabolites in skin and seeds through the reduction of berry size [4] and upregulation of genes [5]. 
Hochberg et al. [40] compared 'Cabernet Sauvignon' and 'Shiraz', with iso- and anisohydricbehaviours, respectively, and found that 'Cabernet Sauvignon' was characterized by milder metabolic perturbations. This result was probably due to a tighter regulation of the stomata upon stress induction during water stress. The same authors suggested a link between vine hydraulics and changes deficit in berry skin metabolism driven by water, with significant consequences on the metabolic composition of the fruit. In contrast, in our experiment, positive effects of water stress on berry composition were observed in 'Cannonau', characterized by isohydric behaviour, whereas no significant effect was observed on total anthocyanins or total phenolics in 'Merlot' and 'Sangiovese', categorized as anisohydric cultivars.

The specific characteristics of the cultivars may have influenced the synthesis of metabolites in different ways. Greater stomatal control could favour a better management of the soil water reserve reducing the water loss by transpiration. In fact, the timing of stress occurrence and its severity could lead to negative effects on phenolic compound concentrations [41]. In our experiment, except for 'Sangiovese' in 2017, secondary metabolite accumulation in'Merlot' and 'Sangiovese' was never affected by water stress conditions. However, as for TSS, the observed significant differences could be attributed to a 'concentration effect' in the berries.

Several studies have highlighted the role of ABA in the control of grape berry maturation. A recent study conducted by Rossdeutsch et al. [42] stated that, based on ABA metabolism and signalling pathways, Vitis genotypes can be segregated by both their genetic background and drought tolerance level. In our experimental work we did not evaluate endogenous ABA but we have used a commercial product, carefully following the doses and times indicated by the producer. Many authors reported that ABA application can promote sugar accumulation [43,44]. In contrast, our results are in agreement with those shown by Jeong et al. [15] and Peppi et al. [16], who reported little or no effect on berry sugar content at harvest when exogenous ABA was applied.

While many researchers have studied the effect of application of ABA on berry composition, limited studies have evaluated the combined effect of exogenous ABA and water stress conditions. Deis et al. [20], working on the combined effect of exogenous ABA and water stress, showed that anthocyanin accumulation was higher and similar in magnitude when exogenous ABA and water stress were applied. Our studies did not show any significant influence of ABA application. However, during our experiment, we did not observe any particular effect on secondary metabolites or skin thickness in vines when subjected to exogenous ABA application. Balint and Reynolds [43] stated that a cool and a wet growing season enhanced the effect of exogenous ABA on fruit composition, hypothesizing that the application of exogenous ABA onto vines could mimic the positive effects of moderate stress. The contrary results observed in our work could be attributed to our local climatic conditions, characterized by high temperatures and low rainfall during the growing season. The ABA concentration is generally proportional to the water limitation level imposed on the plant $[45,46]$. Thus, we hypothesize that environmental conditions and water stress masked the effects of exogenous abscisic acid. In fact, while ABA application onto vines can mimic the positive effects of moderate stress in cool and wet climates [43], such effects would be masked under conditions of severe water and thermal stress.

With regards to the variability among cultivars, different behaviors could be explained by intrinsic cultivar characteristics. In fact, water deficits nearly doubled ABA concentration within the berries of 'Cabernet Sauvignon', whereas it decreased the ABA concentration in 'Chardonnay' at veraison and shortly thereafter [35]. In addition to differences observed in must composition, canopy development was different among cultivars. In 'Merlot' and 'Sangiovese', TLA was composed above all by main leaves both in water stress and well-watered conditions. A different behaviour was observed in the canopy development of 'Cannonau', as the area of secondary leaves was higher than the primary leaf area in well-watered conditions in both 2016 and 2017. Even though the reduction of leaves and shoots is one of the morphological signals in grapevines subjected to water stress [47], the ability to produce leaf area, controlled also by cultivars [48], differentially influences the physiological and must composition of cultivars, as observed in our experiment. 


\section{Conclusions}

In our environmental conditions, 'Sangiovese' and 'Merlot' experienced severe water stress without adequate water supply, to the extent that the vitality of vines can be compromised. In contrast, 'Cannonau' is better suited to endure hot and dry cultural conditions. Moreover, from a qualitative point of view, the cultivars exhibited different behaviours, since only 'Cannonau' benefited from water restriction in terms of must quality in the two years of experiment. No significant effect of exogenous ABA on any metabolites was observed during the study, except for a slight tendency to promote greater colour in the first year in 'Cannonau'.

In terms of recommendations to growers, water stress is not an appropriate agricultural practice in 'Sangiovese', and especially in 'Merlot', in grape-growing regions characterized by severe water stress, as observed in our environmental conditions. It is crucial that these aspects must also be taken into consideration for new vineyards: The correct choice of rootstock but also the density of the planting as well as shape and size of the canopy will be increasingly fundamental for the success of the vineyard. In contrast, a managed water stress condition may be used to increase secondary metabolite concentration in 'Cannonau'. While few experiments have been conducted in environments characterized by abiotic stresses such as heat and drought, our experiment did not show any positive effects, as stated by other studies carried out in different environmental conditions.

Author Contributions: Formal analysis, M.L.C.; Investigation, M.C. and L.M.; Writing-original draft, M.C. and L.M.; Writing-review \& editing, G.N. All authors have read and agreed to the published version of the manuscript.

Funding: This research received no external funding.

Conflicts of Interest: The authors declare no conflict of interest.

\section{References}

1. Jackson, D.I.; Lombard, P.B. Environmental and management practices affecting grape composition and wine quality-a review. Am. J. Enol. Vitic. 1993, 44, 409-430.

2. Chaves, M.M.; Zarrouk, O.; Francisco, R.; Costa, J.M.; Santos, T.; Regalado, A.P.; Lopes, C.M. Grapevine under deficit irrigation: Hints from physiological and molecular data. Ann. Bot. 2010, 105, 661-676. [CrossRef] [PubMed]

3. Medrano, H.; Tomás, M.; Martorell, S.; Escalona, J.M.; Pou, A.; Fuentes, S.; Flexas, J.; Bota, J. Improving water use efficiency of vineyards in semi-arid regions. A review. Agron. Sustain. Dev. 2015, 35, 499-517. [CrossRef]

4. Roby, G.; Harbertson, J.F.; Adams, D.A.; Matthews, M.A. Berry size and vine water deficits as factors in winegrape composition: Anthocyanins and tannins. Aust. J. Grape Wine Res. 2004, 10, 100-107. [CrossRef]

5. Savoi, S.; Wong, D.C.; Arapitsas, P.; Miculan, M.; Bucchetti, B.; Peterlunger, E.; Castellarin, S.D. Transcriptome and metabolite profiling reveals that prolonged drought modulates the henylpropanoid and terpenoid pathway in white grapes (Vitis vinifera L.). BMC Plant Biol. 2016, 16, 67. [CrossRef]

6. Herrera, J.C.; Hochberg, U.; Degu, A.; Sabbatini, P.; Lazarovitch, N.; Castellarin, S.D.; Peterlunger, E. Grape metabolic response to postveraison water deficit is affected by interseason weather variability. J. Agric. Food Chem. 2017, 65, 5868-5878. [CrossRef]

7. Merli, M.C.; Magnanini, E.; Gatti, M.; Pirez, F.J.; Pueyo, I.B.; Intrigliolo, D.S.; Poni, S. Water stress improves whole-canopy water use efficiency and berry composition of 'Sangiovese' (Vitis vinifera L.) grapevines grafted on the new drought-tolerant rootstock M4. Agric. Water Manag. 2016, 169, 106-114. [CrossRef]

8. Schultz, H.R. Differences in hydraulic architecture account for near-isohydric and anisohydric behavior of two field-grown Vitis vinifera L. cultivars during drought. Plant Cell Environ. 2003, 26, 1393-1405. [CrossRef]

9. Lovisolo, C.; Perrone, I.; Carra, A.; Ferrandino, A.; Flexas, J.; Medrano, H.; Schubert, A. Drought-induced changes in development and function of grapevine (Vitis spp.) organs and in their hydraulic and non-hydraulic interactions at the whole-plant level: A physiological and molecular update. Funct. Plant Biol. 2010, 37, 98-116. [CrossRef]

10. Tombesi, S.; Poni, S.; Palliotti, A. Stress idrico in Vitis vinifera: Variabilità delle risposte fisiologiche intra-specifiche e loro potenziale sfruttamento nella mitigazione degli effetti dei cambiamenti climatici. Italus Hortus 2016, 23, 45-53. 
11. Ferrandino, A.; Lovisolo, C. Abiotic stress effects on grapevine (Vitis vinifera L.): Focus on abscisic acid-mediater consequences on secondary metabolism and berry quality. Environ. Exp. Bot. 2014, 133, 138-147. [CrossRef]

12. Tombesi, S.; Nardini, A.; Frioni, T.; Soccolini, M.; Zadra, C.; Farinelli, D.; Poni, S.; Palliotti, A. Stomatal closure is induced by hydraulic signals and maintained by ABA in drought-stressed grapevine. Sci. Rep. 2015, 5, 1-12. [CrossRef] [PubMed]

13. Ruiz-Garcia, Y.; Gil-Munoz, R.; Maria Lopez-Roca, J.; Martinez-Cutillas, A.; Romero-Cascales, I.; Gomez-Plaza, E. Increasing the phenolic compound contentof grapes by preharvest application of abcisic acid and a combination of methyljasmonate and benzothiadiazole. J. Agric. Food Chem. 2013, 61, 3978-3983. [CrossRef] [PubMed]

14. Pilati, S.; Bagagli, G.; Sonego, P.; Moretto, M.; Brazzale, D.; Castorina, G.; Simoni, L.; Tonelli, C.; Guella, G.; Engelen, K.; et al. Abscisic acid is a major regulator of grape berry ripening onset: New insights into ABA signaling network. Front. Plant Sci. 2017, 8, 1093. [CrossRef] [PubMed]

15. Jeong, S.T.; Goto-Yamamoto, N.; Kobayashi, S.; Esaka, M. Effects of plant hormones and shading on the accumulation of anthocyanins and the expression of anthocyanin biosynthetic genes in grape berry skins. Plant Sci. 2004, 167, 247-252. [CrossRef]

16. Peppi, M.C.; Fidelibus, M.W.; Dokoozlian, N. Abscisic Acid Application Timing and Concentration Affect Firmness, Pigmentation, and Color of Flame Seedless' Grapes. HortScience 2006, 41, 1440-1445. [CrossRef]

17. Castellarin, S.D.; Gambetta, G.A.; Wada, H.; Krasnow, M.N.; Cramer, G.R.; Peterlunger, E.; Shakel, K.A.; Matthews, M.A. Characterization of major ripening events during softening in grape: Turgor, sugar accumulation, abscisic acid metabolism, colour development, and their relationship with growth. J. Exp. Bot. 2015, 67, 709-722. [CrossRef] [PubMed]

18. Niculcea, M.; López, J.; Sánchez-Díaz, M.; Carmen Antolín, M. Involvement of berry hormonal content in the response to pre-and post-veraison water deficit in different grapevine (Vitis vinifera L.) cultivars. Aust. J. Grape Wine Res. 2014, 20, 281-291. [CrossRef]

19. de Fernandes Oliveira, A.S.; Nieddu, G. Deficit Irrigation Strategies in Vitis vinifera L. 'Cannonau' under Mediterranean Climate. Part II-Cluster Microclimate and Anthocyanin Accumulation Patterns. S. Afr. J. Enol. Vitic. 2013, 34, 184-196.

20. Deis, L.; Cavagnaro, B.; Bottini, R.; Wuilloud, R.; Silva, M.F. Water deficit and exogenous ABA significantly affect grape and wine phenolic composition under in field and in-vitro conditions. Plant Growth Regul. 2011, 65, 11-21. [CrossRef]

21. Van Leeuwen, C.; Tregoat, O.; Choné, X.; Bois, B.; Pernet, D.; Gaudillère, J.P. Vine water status is a key factor in grape ripening and vintage quality for red Bordeaux wine. How can it be assessed for vineyard management purposes. OENO One 2009, 43, 121-134. [CrossRef]

22. Lorenz, D.H.; Eichhorn, K.W.; Bleiholder, H.; Klose, R.; Meier, U.; Weber, E. Growth Stages of the Grapevine: Phenological growth stages of the grapevine (Vitis vinifera L. ssp. vinifera)—Codes and descriptions according to the extended BBCH scale. Aust. J. Grape Wine Res. 1995, 1, 100-103. [CrossRef]

23. Ferrara, G.; Mazzeo, A.; Matarrese, A.M.S.; Pacucci, C.; Punzi, R.; Faccia, M.; Trani, A.; Gambacorta, G. Application of abscisic acid (S-ABA) and sucrose to improve colour, anthocyanin content and antioxidant activity of Crimson Seedless grape berries. Aust. J. Grape Wine Res. 2015, 21, 18-29. [CrossRef]

24. Di Stefano, R.; Cravero, M.C. The grape phenolic determination. Riv. Vitic. Enol. 1991, 49, 37-45.

25. Dal Santo, S.; Palliotti, A.; Zenoni, S.; Tornielli, G.B.; Fasoli, M.; Paci, P.; Tombesi, S.; Frioni, T.; Bellincontro, A.; d'Onofrio, C.; et al. Distinct transcriptome responses to water limitation in isohydric and anisohydric grapevine cultivars. BMC Genom. 2016, 17, 815. [CrossRef]

26. Anderson, K. Changing varietal distinctiveness of the world's wine regions: Evidence from a new global database. J. Wine Econ. 2014, 9, 249-272. [CrossRef]

27. Calò, A.; Scienza, A.; Costacurta, A. Vitigni D’Italia; Calderini Edagricole: Bologna, Italy, 2001; pp. 540-541.

28. Mercenaro, L.; Nieddu, G.; Porceddu, A.; Pezzotti, M.; Camiolo, S. Sequence polymorphisms and structural variations among four grapevine (Vitis vinifera L.) cultivars representing Sardinian agriculture. Front. Plant Sci. 2017, 8, 1279. [CrossRef]

29. Mercenaro, L.; Usai, G.; Fadda, C.; Nieddu, G.; Del Caro, A. Intra-varietal Agronomical Variability in Vitis vinifera L.'Cannonau' investigated by fluorescence, texture and colorimetric analysis. S. Afr. J. Enol. Vitic. 2016, 37, 67-78. [CrossRef] 
30. Castellarin, S.D.; Bucchetti, B.; Falginella, L.; Peterlunger, E. Influenza del deficit idrico sulla qualità delle uve: Aspetti fisiologici e molecolari. Italus Hortus 2011, 18, 63-79.

31. Poni, S.; Bernizzoni, F.; Civardi, S. Response of "'Sangiovese'” grapevines to partial root-zone drying: Gas-exchange, growth and grape composition. Sci. Hortic. 2007, 114, 96-103. [CrossRef]

32. Chone, X.; Van Leeuwen, C.; Dubourdieu, D.; Gaudillère, J.P. Stem water potential is a sensitive indicator of grapevine water status. Ann. Bot. 2001,87,477-483. [CrossRef]

33. Palliotti, A.; Tombesi, S.; Frioni, T.; Famiani, F.; Silvestroni, O.; Zamboni, M.; Poni, S. Morpho-structural and physiological response of container-grown 'Sangiovese' and Montepulciano cvv. (Vitis vinifera) to re-watering after a pre-veraison limiting water deficit. Funct. Plant Biol. 2014, 41, 634-647. [CrossRef]

34. Córdoba, E.; Bouzas-Cid, Y.; Orriols-Fernández, I.; Mirás-Avalos, J.M. Effects of deficit irrigation on the performance of grapevine (Vitis vinifera L.) 'Godello' and 'Treixadura' in Ribeiro, NW Spain. Agric.Water Manag. 2015, 161, 20-30. [CrossRef]

35. Deluc, L.G.; Quilici, D.R.; Decendit, A.; Grimplet, J.; Wheatley, M.D.; Schlauch, K.A.; Cramer, G.R. Water deficit alters differentially metabolic pathways affecting important flavor and quality traits in grape berries of Cabernet Sauvignon and Chardonnay. BMC Genom. 2009, 10, 212. [CrossRef]

36. Salón, J.L.; Chirivella, C.; Castel, J.R. Response of Bobal to timing of deficit irrigation in Requena, Spain: Water relations, yield, and wine quality. Am. J. Enol. Vitic. 2005, 56, 1-8.

37. Girona, J.; Mata, M.; Del Campo, J.; Arbonés, A.; Bartra, E.; Marsal, J. The use of midday leaf water potential for scheduling deficit irrigation in vineyards. Irrig. Sci. 2006, 24, 115-127. [CrossRef]

38. Bucchetti, B.; Matthews, M.A.; Falginella, L.; Peterlunger, E.; Castellarin, S.D. Effect of water deficit on 'Merlot' grape tannins and anthocyanins across four seasons. Sci. Hortic. 2011, 128, 297-305. [CrossRef]

39. Merli, M.C.; Gatti, M.; Galbignani, M.; Bernizzoni, F.; Magnanini, E.; Poni, S. Comparison of whole-canopy water use efficiency and vine performance of'Sangiovese' (Vitis vinifera L.) vines subjected to a post-veraison water deficit. Sci. Hortic. 2015, 185, 113-120. [CrossRef]

40. Hochberg, U.; Degu, A.; Fait, A.; Rachmilevitch, S. Near isohydric grapevine cultivar displays higher photosynthetic efficiency and photorespiration rates under drought stress as compared with near anisohydric grapevine cultivar. Physiol. Plant 2012, 147, 443-452. [CrossRef]

41. Ojeda, H.; Andary, C.; Kraeva, E.; Carbonneau, A.; Deloire, A. Influence of pre-and postveraison water deficit on synthesis and concentration of skin phenolic compounds during berry growth of Vitis vinifera Shiraz. Am. J. Enol. Vitic. 2002, 53, 261-267.

42. Rossdeutsch, L.; Edwards, E.; Cookson, S.J.; Barrieu, F.; Gambetta, G.A.; Delrot, S.; Ollat, N. ABA-mediated responses to water deficit separate grapevine genotypes by their genetic background. BMC Plant Biol. 2016, 16, 91. [CrossRef]

43. Balint, G.; Reynolds, A.G. Impact of exogenous abscisic acid on vine physiology and grape composition of Cabernet Sauvignon. Am. J. Enol. Vitic. 2012, 64, 74-87. [CrossRef]

44. Hiratsuka, S.; Onodera, H.; Kawai, Y.; Kubo, T.; Itoh, H.; Wada, R. ABA and sugar effects on anthocyanin formation in grape berry cultured in vitro. Sci. Hortic. 2001, 90, 121-130. [CrossRef]

45. Ribaut, J.M.; Pilet, P.E. Effects of water stress on growth, osmotic potential and abscisic acid content of maize roots. Physiol. Plant 1991, 81, 156-162. [CrossRef]

46. Liu, F.; Jensen, C.R.; Andersen, M.N. Pod set related to photosynthetic rate and endogenous ABA in soybeans subjected to different water regimes and exogenous ABA and BA at early reproductive stages. Ann. Bot. 2004, 94, 405-411. [CrossRef]

47. Gómez-del-Campo, M.; Ruiz, C.; Lissarrague, J.R. Effect of water stress on leaf area development, photosynthesis, and productivity in Chardonnay and Airén grapevines. Am. J. Enol. Vitic. 2002, 53, 138-143.

48. Stevens, R.M.; Harvey, G.; Aspinall, D. Grapevine growth of shoots and fruit linearly correlate with water stress indices based on root-weighted soil matric potential. Aust. J. Grape Wine Res. 1995, 1, 58-66. [CrossRef]

(C) 2020 by the authors. Licensee MDPI, Basel, Switzerland. This article is an open access article distributed under the terms and conditions of the Creative Commons Attribution (CC BY) license (http://creativecommons.org/licenses/by/4.0/). 